\title{
FUNCTIONAL STRATEGIES OF THE ENTERPRISE: ESSENCE AND CLASSIFICATION
}

Аннотация. В статье раскрыта сущность функииональных стратегий предприятия, их особенности и значение, систематизирована типология функииональных стратегий с разбивкой их по подвидам.

Ключевые слова: стратегия, функииональная стратегия, классификаиия стратегий.

Abstract. The article reveals the essence of functional strategies of the enterprise, their features and importance, systematized typology of functional strategies with their breakdown by subspecies.

Keywords: strategy, functional strategy, strategy classification.

В современных рыночных условиях, когда наблюдается усиление конкуренции, диверсификация персонала, функционирование и развитие предприятий и организаций невозможно без разработки четкой стратегии.

В современной литературе по стратегическому управлению большое внимание уделяется рассмотрению вопросов по формированию общей стратегии развития предприятия, в то время как проблемам выбора функциональных стратегий, и даже раскрытию их понятия, особенностей и вообще типологии уделяется мало внимания. Хотя от того, как правильно будет выбрана стратегия в конкретной функциональной области деятельности предприятия, во многом будет зависеть эффективность общей стратегии дальнейшего развития предприятия.

Далее раскроем сущность и особенности разработки и реализации функциональных стратегий предприятия.

Деятельность любого предприятия, не зависимо от формы собственности, тесно связана с одновременным выполнением различных специфических функций, в рамках которых необходима выработка стратегий с целью обеспечения стабильного положения предприятия в долгосрочной перспективе.

Таким образом, можно сформулировать следующее понятие функциональной стратегии: функциональная стратегия - это часть общей стратегии предприятия, определяющая стратегический ориентир конкретной функциональной области управления предприятием, которая обеспечивает ему достижение поставленной цели.

Целью функциональной стратегии является распределение ресурсов отдела (службы), поиск эффективного поведения функционального подразделения в рамках общей стратегии. Каждая функциональная стратегия должна содержать:

1) цели, условия, основные направления деятельности отдельных подразделений;

2) порядок, последовательность решения задач, мероприятия и средства для достижения поставленных целей.

В месте с тем надо отметить, что все функциональные стратегии тесно связаны между собой, например, от того, как будет разработана стратегия управления персоналом, будет зависеть достижение заданного объема производства продукции и ее качество, а это скажется на объемах реализации продукции, определенных в рамках стратегии маркетинга.

Как уже отмечалось выше, предприятию приходится действовать в различных сферах деятельности, поэтому считаем необходимым изучить более подробно типологию функциональных стратегий, представленную в литературных источниках.

Так, Ханс Виссема [1] в своей книге «Стратегический менеджмент и предпринимательство: возможности для будущего процветания» отводит функциональным стратегиям поддерживающую и обслуживающую роль по отношению ко всем сферам бизнеса, 
упор делая на финансовой стратегии развития предприятия.

Попов С.А. в книге «Стратегический менеджмент: Видение - важнее, чем знание» [2] из всего многообразия стратегий функциональных подсистем выделяет производственную стратегию, стратегию управления персоналом, финансовую стратегию и продуктово-маркетинговую стратегию.

В работах Хасси Д. [3], Веснина В.Р. [4], Марковой В.Д. и Кузнецовой С.А. [5], Добреньковой Е.В. и Долгорукова А.М. [6], Виханского О.С. [7], Гапоненко А.Л. и Панкрухина А.П. [8], Шершневой 3.Е. [9], Парахиной В.Н., Максименко Л.С. и Панасенко С.В. [10], Савельевой Н.А. [11] также выделяют стратегии, рассмотренные в работах Попова С.А.

Маркова В.Д. и Кузнецова С.А. помимо вышеперечисленных выделяют информационную стратегию, необходимую для разработки и управления информационными потоками на предприятии в целях совершенствования процесса принятия решений.

Шершнева 3.Е. в своей работе расширяет список типов функциональных стратегий, а именно выделяя стратегию материально-технического обеспечения предприятия.

Парахина В.Н., Максименко Л.С., Панасенко С.В. присоединяют к общепринятым стратегиям стратегию научно-технического развития и технической политики организации или, иначе говоря, инновационную стратегию.

Савельева Н.А. в свою очередь выделяет также стратегию внешнеэкономической деятельности предприятия, которая представляет собой процесс изучения мирового рынка, определения глобальной и локальных целей внешнеэкономической деятельности предприятия.

Значительная работа, посвященная проблемам выработки функциональных стратегий, была издана в 2017 г. авторами Абрамовым С.В. и Абрамовым В.С. [12], которые подробно раскрыли сущность и особенности стратегии маркетинга, финансовой стратегии, инновационной стратегии, стратегии управления персоналом, стратегии развития информационных технологий, расширив этот список, добавив кроме этих стратегий также инвестиционную стратегию, рассматриваемую ими как документ предприятия, в котором определены основные направления его инвестиционной деятельности; стратегию управления рисками, как документ предприятия, где определены основные направления управления рисками, которые возникают в деятельности предприятия; стратегию корпоративной социальной ответственности, связанную с ответственностью предприятия за воздействие его решений и деятельности на общество и окружающую среду через прозрачное и этичное поведение, и стратегию ведения переговоров.

Таким образом, обобщив вышесказанное, можно составить общий перечень функциональных стратегий, выделенных в литературе по стратегическому управлению, это: производственная стратегия, стратегия маркетинга, стратегия управления персоналом, финансовая стратегия, стратегия материально-технического обеспечения предприятия, товарная стратегия, информационная стратегия, инновационная стратегия, стратегия внешнеэкономической деятельности предприятия, инвестиционная стратегия, стратегия управления рисками, стратегия корпоративной социальной ответственности и стратегия ведения переговоров.

Автор, в свою очередь, считает, что данный список не охватывает всех сфер деятельности предприятия, поэтому к представленному выше списку необходимо добавить также стратегию ценообразования и экологическую стратегию.

Также хочется отметить, что исследователи в области стратегического управления раскрывают только сущность определенных ими стратегий, не уточняя их разновидности. Хотя выделение подвидов стратегий очень важно, поскольку каждый из них по-разному действует в конкретной ситуации.

Далее раскроим сущность каждой из определенных выше стратегий и выделим их разновидности. Классификация стратегий на подвиды составлена на основе изучения научной литературы по конкретным сферам бизнеса предприятия.

Производственная стратегия - это часть общей стратегии предприятия, представляющая собой программу долгосрочных действий по производству и продвижению продукции с целью повышения конкурентных преимуществ предприятия.

В литературе выделяют две разновидности производственной стратегии - стратегию производственных процессов и стратегию размещения производства. 
Стратегия производственных процессов вырабатывает решения, определяющие способы трансформации ресурсов в готовую продукцию.

Стратегия размещения производства вырабатывает решения по выбору места размещения производства продукции.

Стратегия маркетинга - это часть общей стратегии предприятия, которая определяет цели предприятия в области маркетинга на соответствующем сегменте рынка.

Выделяют портфельную маркетинговую стратегию, связанную с совершенствованием ассортимента продукции, стратегию роста, направленную на выработку решений по увеличению доходности компании, стратегии создания конкурентных преимуществ, определяющие способы выхода предприятия на рынок и методы конкурентной борьбы.

Стратегия управление персоналом это часть общей стратегии предприятия, ставящая целью формирование конкурентоспособного потенциала персонала предприятия, позволяющего ему занимать стабильную позицию на рынке.

Разновидностями стратегии управления персоналом являются следующие стратегии:

- стратегия ориентации на свои силы, позволяющая сформировать группу специалистов, готовых производить и реализовывать будущие новые изделия в рамках своего предприятия;

- стратегия приобретения готовых специалистов;

- стратегия приема небольшого количества высококвалифицированных специалистов (выполнение всей работы небольшим количеством высококвалифицированных специалистов);

- стратегия приема специалистов средней квалификации, но в достаточном количестве;

- стратегию ориентации на индивидуальную работу, т.е. когда работа каждого зависит только от него самого, команда при этом не создается;

- стратегия ориентации на работу в команде.

Финансовая стратегия, как составляющая общей стратегии предприятия, означает выработку решений по своевременному обеспечению предприятия финансовыми ресурсами, и включает:
- генеральную финансовую стратегию, определяющую финансовую деятельность всего предприятия;

- оперативную финансовую стратегию, обеспечивающую контроль расходования средств и выявление внутренних резервов;

- стратегию достижения частных целей, которая заключается в эффективном выполнении финансовых операций, направленных на обеспечение реализации главной стратегической цели.

Стратегия материально-технического обеспечения предприятия - это решения, направленные на совершенствование процесса получения и доставки предприятию средств и предметов труда в сроки и в количествах, обеспечивающих его устойчивую производственную деятельность. Разновидностями стратегии являются:

- стратегия управления запасами - это комплекс мероприятий по созданию и пополнению запасов, организации их непрерывного контроля;

- стратегия логистики - это решения, связанные с управлением цепью поставок.

Товарная стратегия - это стратегия, обеспечивающая принятие решений по поддержанию конкурентоспособности товаров предприятия. В рамках этой стратегии можно выделить:

- стратегию инновации, которая ориентирована на формирование решений по разработке и внедрению новых товаров и услуг;

- стратегию вариации, которая связана с модифицированием и дифференцированием товаров и услуг;

- стратегию сохранения, целью которой является сохранение основного продукта и всего ассортимента в целом;

- стратегию устранения, направленную на исключение из ассортимента менее привлекательных или нерентабельных товаров и услуг.

Инновационная стратегия - это комплекс решений по определению способов перевода предприятия из существующего положения в новое (целевое) состояние на основе внедрения инноваций (нововведений).

Существует много разновидностей стратегии:

- наступательная инновационная стратегия ориентирована на самостоятельную разработку инноваций;

- защитная (оборонительная) стратегия применяется предприятием, имеющим проч- 
ные позиции на рынке и желающим сохранить их;

- промежуточная стратегия основана на дифференциации продукции и стремлении удерживать преимущества на рынке;

- поглощающая стратегия (лицензирование) ориентирована на применение инновационных разработок других организаций.

Информационная стратегия включает вопросы планирования стратегии развития информационной системы предприятия.

Стратегия инвестиционной деятельности - это решения, направленные на поиск путей активного управления инвестициями, позволяющих получить дополнительную прибыль по сравнению с той, которая лишь компенсирует дополнительный риск. Типами инвестиционной стратегии являются:

- консервативная или пассивная инвестиционная стратегия, когда вложения в какие-либо объекты практически не грозят потерей инвестированного капитала, но и наблюдается очень низкая их прибыльность;

- умеренная (компромиссная) инвестиционная стратегия, которая рассчитана на получение среднего дохода от инвестиционной деятельности;

- агрессивная инвестиционная стратегия, предполагающая получение максимального дохода, но и связанная с большими рисками потери вложенного капитала;

- смешанная инвестиционная стратегия основана на сочетании различных инвестиционных стратегий с целью снижения рисков, но и получения доходов.

Стратегия ведения переговоров - это выработка основных направлений, целей и задач ведения переговоров.

Основные стратегии ведения переговоров могут выступать в следующих варианTax:

- «проигрыш-проигрыш» - возникает в том случае, если участники переговоров находятся в одинаковом состоянии упрямства, авторитарности, решительности, не уступая друг другу, что грозит тем, что результат переговоров не будет достигнут;

- «выигрыш-проигрыш», когда один участник переговоров стремится добиться результата за счет интересов другого участника (например, получение клиентом скидки у продавца);

- «проигрыш-выигрыш» означает отказ от собственных интересов в пользу другого участника переговоров, например, более сильного партнера или вышестоящей организации;

- «компромисс» предполагает достижение результата переговоров его участниками путем уступок друг другу в некоторых моментах;

- «выигрыш-выигрыш», при котором результат переговоров выгоден для всех.

Стратегия корпоративной социальной ответственности (КСО) - это комплекс мероприятий, связанный с социальной ответственностью бизнеса перед обществом. Выделяют два вида стратегий КСО - внешнюю, связанную с социальной ответственностью предпринимателей перед внешней средой, и внутреннюю, которая характеризуется как ответственность бизнеса перед собственным персоналом.

Стратегия ценообразования - это набор действий по установлению цен на продукцию на рынках, на которых действует предприятие. Выделяют несколько разновидностей стратегий ценообразования в зависимости от целей, которые ставит перед собой предприятие:

- стратегия высоких цен, при которой целью предприятия при установлении цены является возможность «сбора урожая» с тех потребителей, которые очень заинтересованы в товаре и готовы заплатить за него даже высокие цены;

- стратегия средних цен - это установление справедливой, по мнению предприятия, цены, обеспечивающей ему стабильное положение на рынке и исключающей ценовую войну по отношению к конкурентам;

- стратегия низких цен, устанавливаемых с целью завоевания новых сегментов рынка;

- стратегия целевых цен, которые устанавливаются с целью достижения определенного объема прибыли;

- стратегия льготных цен, при которой цены устанавливаются с учетом предоставленной покупателю скидки;

- стратегия «следования за лидером» предполагает установление цен на продукцию с учетом ценовой политики лидера рынка или отрасли;

- стратегия неизменных цен направлена на сохранение неизменных цен на протяжении длительного периода;

- стратегия неокругленных или психологических цен, как свидетельство желания 
компании установить их на минимальном уровне;

- и др.

Хотелось бы отметить, что стратегий ценообразования выделено намного больше, но выше представлены наиболее часто используемые предприятиями и организациями.

Экологическая стратегия представляет собой программу действий предприятия по совершенствованию мероприятий в области охраны окружающей среды и использования природных ресурсов. Причем различают пассивную стратегию, при которой предприятие действует в рамках выполнения существующих экологических законов, стандартов, нормативов, и активную стратегию, ориентированную на то, чтобы совершенствовать экологические мероприятия на основе глобального изменения продукта, технологии, поднятия уровня компетенции персонала и т.Д.

Стратегия управления рисками представляет собой систему мер по достижению конкурентных преимуществ предприятия за счет выбора эффективного способа управления возникающими в процессе его деятельности рисками. являются:

Видами стратегий управления рисками

- безрисковая стратегия, позволяющая избежать негативных последствий рисковых ситуаций, т.к. они не окажут значительного влияния на активы предприятия;

- стратегия принятия риска, при которой руководство предприятия не пытается повлиять на риск, а принимает его, что может сказаться на возможности получения прибыли;

- стратегия превентивного воздействия на риск, которая предполагает разработку мер по предотвращению появления рисковых факторов и снижению вероятности получения ущерба;

- стратегия последующего воздействия на риск, ориентированная на принятие мер по уменьшению воздействия последствий возникшего риска на деятельность предприятия.

И, наконец, стратегия внешнеэкономической деятельности - это система мер по созданию и координированию своих действий на внешних рынках.

Типология стратегий внешнеэкономической деятельности по мнению ученых соответствует видам стратегий маркетинга, которые выбирает предприятие на внутреннем рынке, т.е. от того, какую цель ставить предприятие на внешней рынке, и выбирается соответствующая стратегия маркетинга.

В таблице 1 представим обобщенную типологию функциональных стратегий и их разновидности.

Таблица 1 - Типология функциональных стратегий

\begin{tabular}{|c|c|}
\hline $\begin{array}{c}\text { Тип } \\
\text { стратегии }\end{array}$ & Разновидности \\
\hline Стратегия маркетинга & $\begin{array}{l}\text { - портфельная стратегия; } \\
\text { - стратегия роста; } \\
\text { - стратегии создания конкурентных преимуществ }\end{array}$ \\
\hline Производственная стратегия & $\begin{array}{l}\text { - стратегия производственных процессов; } \\
\text { - стратегия размещения производства }\end{array}$ \\
\hline Финансовая стратегия & $\begin{array}{l}\text { - генеральная финансовая стратегия; } \\
\text { - оперативная финансовая стратегия; } \\
\text { - стратегия достижения частных целей }\end{array}$ \\
\hline $\begin{array}{l}\text { Стратегия управления персона- } \\
\text { лом }\end{array}$ & $\begin{array}{l}\text { - стратегия ориентации на свои силы; } \\
\text { - стратегия приобретения готовых специалистов; } \\
\text { - стратегия приема небольшого количества высококвали- } \\
\text { фицированных специалистов (выполнение всей работы } \\
\text { небольшим количеством высококвалифицированных спе- } \\
\text { циалистов); } \\
\text { - стратегия приема специалистов средней квалификации, } \\
\text { но в достаточном количестве; } \\
\text { - стратегия ориентации на индивидуальную работу; } \\
\text { - стратегия ориентации на работу в команде }\end{array}$ \\
\hline
\end{tabular}




\begin{tabular}{|c|c|}
\hline $\begin{array}{l}\text { Стратегия } \\
\text { технического обериально- } \\
\text { изводства }\end{array}$ & $\begin{array}{l}\text { - стратегия управления запасами; } \\
\text { - стратегия логистики }\end{array}$ \\
\hline Товарная стратегия & $\begin{array}{l}\text { - стратегия инновации; } \\
\text { - стратегия вариации; } \\
\text { - стратегия сохранения; } \\
\text { - стратегия устранения }\end{array}$ \\
\hline Инновационная стратегия & $\begin{array}{l}\text { - наступательная инновационная стратегия; } \\
\text { - защитная (оборонительная) стратегия; } \\
\text { - промежуточная стратегия; } \\
\text { - поглощающая стратегия (лицензирование) }\end{array}$ \\
\hline \multicolumn{2}{|l|}{ Информационная стратегия } \\
\hline $\begin{array}{l}\text { Стратегия инвестиционной дея- } \\
\text { тельности }\end{array}$ & $\begin{array}{l}\text { - консервативная (пассивная) стратегия; } \\
\text { - умеренная (компромиссная) стратегия; } \\
\text { - агрессивная стратегия; } \\
\text { - смешанная стратегия }\end{array}$ \\
\hline Стратегия ведения переговоров & $\begin{array}{l}\text { - стратегия «проигрыш-проигрыш»; } \\
\text { - стратегия «выигрыш-проигрыш»; } \\
\text { - стратегия «проигрыш-выигрыш»; } \\
\text { - стратегия «компромисс»; } \\
\text { - стратегия «выигрыш-выигрыш» }\end{array}$ \\
\hline $\begin{array}{l}\text { Стратегия корпоративной соци- } \\
\text { альной ответственности }\end{array}$ & $\begin{array}{l}\text { - внешняя стратегия; } \\
\text { - внутренняя стратегия }\end{array}$ \\
\hline Стратегия ценообразования & $\begin{array}{l}\text { - стратегия высоких цен; } \\
\text { - стратегия средних цен; } \\
\text { - стратегия низких цен; } \\
\text { - стратегия целевых цен; } \\
\text { - стратегия льготных цен; } \\
\text { - стратегия «следования за лидером»; } \\
\text { - стратегия неизменных цен; } \\
\text { - стратегия неокругленных цен и др. }\end{array}$ \\
\hline Экологическая стратегия & $\begin{array}{l}\text { - активная стратегия; } \\
\text { - пассивная стратегия }\end{array}$ \\
\hline Стратегия управления рисками & $\begin{array}{l}\text { - безрисковая стратегия; } \\
\text { - стратегия принятия риска; } \\
\text { - стратегия превентивного воздействия на риск; } \\
\text { - стратегия последующего воздействия на риск }\end{array}$ \\
\hline $\begin{array}{l}\text { Стратегия внешнеэкономической } \\
\text { деятельности }\end{array}$ & $\begin{array}{l}\text { - портфельная стратегия; } \\
\text { - стратегия роста; } \\
\text { - стратегии создания конкурентных преимуществ }\end{array}$ \\
\hline
\end{tabular}

Таким образом, в статье представлен авторский взгляд на выделение типов функциональных стратегий. Считаем, что предложенная типология позволит обеспечить более точную идентификацию каждой функциональной стратегии, определить их место среди других видов стратегий. По нашему мнению, для того, чтобы предприятие достигло успеха в своей деятельности, все функциональные стратегии должны быть согласованы и тесно взаимодействовать друг с другом.

\section{СПИСОК ЛИТЕРАТУРЫ}

1. Виссема X. Стратегический менеджмент и предпринимательство: возможности для будущего процветания: пер. с англ. М.: Финпресс, 2000.
2. Попов С.А. Стратегический менеджмент: Видение - важнее, чем знание: Учебное пособие. М.: Дело, 2003. 
3. Хасси Д. Стратегия и планирование: пер. с англ.; под ред. Л.А. Трофимовой. СПб.: Питер, 2001.

4. Веснин В.Р. Стратегическое управление: Учебник. М.: ТК Велби, Изд-во Проспект, 2004.

5. Маркова В.Д., Кузнецова С.А. Стратегический менеджмент: Курс лекций. М.: ИНФРА-М; Новосибирск: Сибирское соглашение, 2002.

6. Добренькова Е.В., Долгоруков А.М. Стратегическое управление бизнесом: Монография. М.: Международный университет бизнеса и управления, 2001.

7. Виханский О.С. Стратегическое управление: Учебник. - 2-е изд., перераб. и доп. М.: Гардарики, 2000.
8. Гапоненко А.Л., Панкрухин А.П. Стратегическое управление: Учебник. М.: Омега-Л, 2004.

9. Шершнева 3.Е. Стратегическое управление: Учебник. - 2-е изд., перераб. и доп. М.: Финансы и статистика, 2004.

10. Парахина В.Н., Максименко Л.С., Панасенко С.В. Стратегический менеджмент: Учебник. М.: КНОРУС, 2005.

11. Савельева Н.А. Стратегический менеджмент: Учебник. Ростов н/Д.: Феникс, 2012.

12. Абрамов В.С., Абрамов С.В. Стратегический менеджмент. В 2 ч. Часть 2. Функциональные стратегии: Учебник и практикум для бакалавриата и магистратуры; под ред. В.С. Абрамова. М.: Юрайт, 2017. к.э.н., дочент, дочент кафедры «Экономика, маркетинг и психология управления», ФГБОУ ВО «Ангарский государственный технический университет», e-mail: chklaukova@mail.ru

Шиверская Анна Георгиевна, обучающаяся кафедры «Экономика, маркетинг и психология управления», ФГБОУ ВО «Ангарский государственный технический университет», e-mail: anna.angarsk@inbox.ru

\section{ПРАКТИКА ПРИМЕНЕНИЯ ФАКТОРИНГА НА ПРЕДПРИЯТИИ}

Cheklaukova E.L., Shiverskaya A.G.

\section{THE PRACTICE OF FACTORING IN THE ENTERPRISE}

Аннотация. $B$ статье рассмотрен опыт использования факторинга на предприятии с целью сокращения зависимости от дебиторов. На основе анализа фирм-факторов в регионе и предлагаемых ими условий выбран оптимальный для предприятия вариант финансирования. $B$ результате рассчитана динамика показателей работы предприятия в плановом периоде $u$ сделан вывод о возможности применения факторинга для финансирования его деятельности.

Ключевые слова: факторинг, фирма-фактор, финансирование предприятия.

Annotation. The article considers the experience of factoring in the enterprise in order to reduce dependence on debtors. Based on the analysis of factor firms in the region and their proposed conditions, the optimal financing option for the enterprise was chosen. As a result, the dynamics of the performance of the enterprise in the planning period is calculated and the conclusion is made about the possibility of using factoring to Finance its activities.

Keywords: the factoring company-the factor, the financing of the enterprise.

В процессе деятельности предприятия может возникнуть ситуация, когда имеется преобладание его краткосрочных обязательств над имеющимися денежными средствами. Это может повлечь за собой невозможность оплаты наиболее срочных обязательств за счет абсолютно ликвидных акти- вов. При этом возрастает риск увеличения операционного и производственного цикла, что негативно может отразиться на финансовых результатах предприятия.

Ситуация дефицита денежных средств типична для многих российских предприятий. Это может объясняться и неумелым 